\title{
Development of a novel mouse model of hepatocellular carcinoma with nonalcoholic steatohepatitis using a high-fat, choline- deficient diet and intraperitoneal injection of diethylnitrosamine
}

Norihiro Kishida', Sachiko Matsuda ${ }^{1,2}$, Osamu Itano ${ }^{1 *}$, Masahiro Shinoda ${ }^{1}$, Minoru Kitago ${ }^{1}$, Hiroshi Yagi ${ }^{1}$, Yuta Abe ${ }^{1}$, Taizo Hibi ${ }^{1}$, Yohei Masugi ${ }^{3}$, Koichi Aiura ${ }^{4}$, Michiie Sakamoto ${ }^{3}$ and Yuko Kitagawa ${ }^{1}$

\begin{abstract}
Background: The incidence of hepatocellular carcinoma with nonalcoholic steatohepatitis is increasing, and its clinicopathological features are well established. Several animal models of nonalcoholic steatohepatitis have been developed to facilitate its study; however, few fully recapitulate all its clinical features, which include insulin resistance, inflammation, fibrosis, and carcinogenesis. Moreover, these models require a relatively long time to produce hepatocellular carcinoma reliably. The aim of this study was to develop a mouse model of hepatocellular carcinoma with nonalcoholic steatohepatitis that develops quickly and reflects all clinically relevant features.

Methods: Three-week-old C57BL/6J male mice were fed either a standard diet (MF) or a choline-deficient, high-fat diet (HFCD). The mice in the MF + diethylnitrosamine (DEN) and HFCD + DEN groups received a one-time intraperitoneal injection of DEN at the start of the respective feeding protocols.

Results: The mice in the HFCD and HFCD + DEN groups developed obesity early in the experiment and insulin resistance after 12 weeks. Triglyceride levels peaked at 8 weeks for all four groups and decreased thereafter. Alanine aminotransferase levels increased every 4 weeks, with the HFCD and HFCD + DEN groups showing remarkably high levels; the HFCD + DEN group presented the highest incidence of nonalcoholic steatohepatitis. The levels of fibrosis and steatosis varied, but they tended to increase every 4 weeks in the HFCD and HFCD + DEN groups. Computed tomography scans indicated that all the HFCD + DEN mice developed hepatic tumors from 20 weeks, some of which were glutamine synthetase-positive.
\end{abstract}

Conclusions: The nonalcoholic steatohepatitis-hepatocellular carcinoma model we describe here is simple to establish, results in rapid tumor formation, and recapitulates most of the key features of nonalcoholic steatohepatitis. It could therefore facilitate further studies of the development, oncogenic potential, diagnosis, and treatment of this condition.

Keywords: Nonalcoholic steatohepatitis, Hepatocellular carcinoma, Diethylnitrosamine, High-fat choline-deficient diet, Mouse model

\footnotetext{
* Correspondence: laplivertiger@gmail.com

${ }^{1}$ Department of Surgery, School of Medicine, Keio University, 35

Shinanomachi, Shinjuku-ku, Tokyo 160-8582, Japan

Full list of author information is available at the end of the article
} 


\section{Background}

Worldwide, hepatocellular carcinoma (HCC) is the fifthmost common cancer in men and seventh-most common in women, and its incidence has continuously increased in recent years [1]. The major risk factors for $\mathrm{HCC}$ are infection with hepatitis B and C viruses; however, the incidence of viral-related HCC has decreased owing to improvements in the management and treatment of viral infections. Meanwhile, the frequency of non-viral HCC-related to alcohol consumption and other factors-has gradually increased. Nonalcoholic fatty liver disease (NAFLD), which is a hepatic manifestation of metabolic syndrome, is one of the most common causes of chronic liver disease and liver cirrhosis in the world $[2,3]$. NAFLD ranges from simple steatosis to nonalcoholic steatohepatitis (NASH) associated with inflammation, fibrosis, and carcinogenesis [4]. In accordance with multiple-hit theory, metabolic syndrome, genetic factors, oxidative stress, inflammatory cytokines, endotoxins, and insulin resistance have been shown to be involved in NASH development and the progression of NASH-HCC [5]. A number of studies describing the natural history of NASH have found liver failure and HCC to be the major causes of death [6-12].

Various genetic and dietary NASH animal models exist. For example, PTEN knockout mice undergo carcinogenesis, and exhibit steatohepatitis, but not obesity, dyslipidemia, or insulin resistance [13]. $o b / o b$ mice are diabetic owing to a defect in the leptin gene and genetically obese; $d b / d b$ mice have a defective leptin receptor gene $[14,15]$. Dietary models include a high-fat diet (HFD) model [16], a high-fat, choline-deficient diet model (HFCD) [17, 18], a methionine- and cholinedeficient diet (MCD) model $[19,20]$. These models require a relatively long period-usually about 1 year-to produce HCC [17]. A 16-week NASH-HCC mouse model based on an HFD combined with low-dose streptozotocin (STZ) has been reported [21]; however, those mice were not insulin resistant, because they exhibited a lack of insulin secretion. The liver carcinogenicity of diethylnitrosamine (DEN) has been reported [22-24], and DEN has been added to the rat NASH-HCC model in combination with an HFD [25-27]. A few models exhibit all the associated clinical features of NASH-HCC, such as insulin resistance, inflammation, fibrosis, and carcinogenesis, such as a high-fat and fructose diet model [28]. Recent genetic and dietary NASH-HCC models have included MUP-uPA transgenic mice with HFD [29] and melanocortin 4 receptor (MC4R) knockout mice with HFD [30].

Since there is no effective treatment or chemoprevention for $\mathrm{HCC}$ related to NASH, a mouse model with the same clinical features as human NASH is needed. In this study, by feeding C57BL/6 mice an
HFCD combined with DEN exposure, we developed a novel experimental NASH-HCC mouse model that exhibits all the relevant clinical features by 20 weeks, including insulin resistance, inflammation, fibrosis, and carcinogenesis.

\section{Methods \\ Animals}

Three-week-old male C57Bl/6J mice were purchased from Oriental Yeast (Tokyo, Japan), housed in a temperature-, humidity-, and ventilation-controlled vivarium, and kept on a 12-h light/dark cycle under specific pathogen-free conditions. For the DEN intraperitoneal (i.p.) experiment, the mice were randomly divided into two groups: the standard diet (MF) group, which was fed an MF (11.4 \% fat, $25.7 \%$ protein, $62.9 \%$ carbohydrate, total calories $359 \mathrm{kcal} / 100 \mathrm{~g}$; purchased from Oriental Yeast); and the HFCD group, which was fed an HFCD (58.0 \% fat, $16.4 \%$ protein, $25.5 \%$ carbohydrate, total calories $556 \mathrm{kcal} / 100 \mathrm{~g}$; purchased from Oriental Yeast) [17]. The two groups were further divided into two subgroups, one of which was treated with DEN. The $\mathrm{MF}+\mathrm{DEN}$ and HFCD + DEN subgroups received a onetime i.p. injection of $25 \mathrm{mg} / \mathrm{kg} \mathrm{DEN}$ at the start of the respective feeding protocols. Food and water were given ad libitum. Five mice from each group were sacrificed every 4 weeks, and their body weights and liver weights measured. An overview of the experimental protocol appears in Fig. 1.

All procedures for animal experimentation were in accordance with the Helsinki Declaration of 1975 and Institutional Guidelines on Animal Experimentation at Keio University. This study was approved by the Keio University Institutional Animal Care and Use Committee (Approval number: 08073).

\section{Measurement of biological parameters}

Serum levels of fasting blood sugar (FBS), alanine aminotransferase (ALT), and triglyceride (TG) were measured using a Fuji Dri-Chem 3500 analyzer (Fuji Film Co. Ltd, Tokyo, Japan). Insulin levels were determined using a mouse insulin enzyme-linked immunoassay kit (Morinaga Institute of Biological Science, Inc. Yokohama, Japan). The quantitative insulin sensitivity check index was calculated as $1 / \log$ (fasting insulin) $+\log$ (fasting glucose). Interleukin (IL)-6, tumor necrosis factor (TNF)alpha, leptin, adiponectin, and C-reactive protein (CRP) levels were measured using Procarta Multiplex Immunoassays (Affymetrix eBioscience, San Diego, CA, USA). Serum amyloid A (SAA) was determined using the PHASE RANGE Mouse SAA ELISA kit (Tridelta Development Ltd., Kildare, Ireland). 


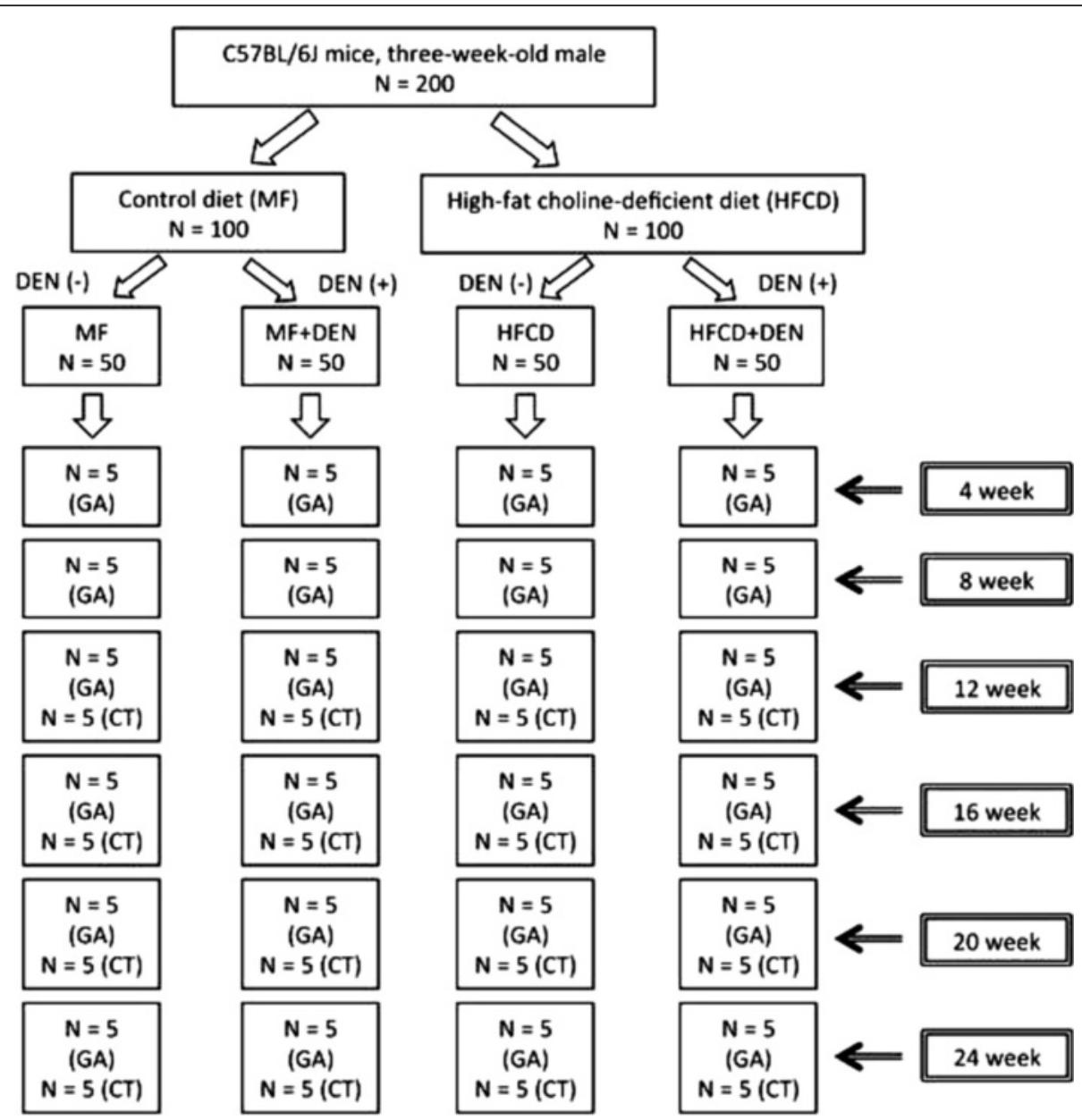

Fig. 1 Overview of the experimental design, showing intraperitoneal diethylnitrosamine (DEN) administration. N, number; GA, general assessment; $\mathrm{CT}$, computed tomography scanning

\section{Insulin tolerance test}

To assess insulin resistance, we performed an insulin tolerance test. Mice were injected with $1 \mathrm{U} / \mathrm{kg}$ of insulin (Humulin R; Eli Lilly Japan, Kobe, Japan), and blood glucose was measured using an Accu-Chek meter (Roche Diagnostics Japan, Tokyo, Japan) every 20 min up to $120 \mathrm{~min}$. The ratio was calculated using the preinjection value as a standard.

\section{Histological analysis}

Liver tissue was assessed grossly, and samples were fixed in $10 \%$ formaldehyde and processed for hematoxylineosin staining. Variables were blindly scored by two experienced hepatopathologists using a modified scoring system adapted from the NAFLD activity score (NAS): macrosteatosis (0-3); lobular inflammatory changes (0-3); hepatocyte ballooning (0-2); and fibrosis scored as portal and perivenular (stage $0-4$ ).

Immunohistochemical detection of F4/80 (a macrophage marker) was performed as follows. Paraffin sections were deparaffinized in xylene, hydrated in a gradient of ethanol, and incubated with proteinase $\mathrm{K}$ for $10 \mathrm{~min}$ at room temperature for antigen retrieval. The sections were then incubated with a primary rat antimouse F4/80 antibody (T-2006; BMA Biomedicals, Augst, Switzerland) overnight at $4{ }^{\circ} \mathrm{C}$, followed by incubation with Histofine Simple Stain mouse MAX-PO (Rat) (Nichirei Bioscience, Tokyo, Japan) for $30 \mathrm{~min}$. Staining was detected using diaminobenzidine tetrahydrochloride. Three light microscopy images at 100 times magnification were taken of each slide to determine the ratio of F4/80-positive cells (macrophages) to hepatocyte nuclei.

Immunostaining for glutamine synthetase (GS) was performed by the Stelic Institute \& Co., Inc. (Tokyo, Japan). Sirius red staining was performed using Van Gieson's stain solution and Sirius red solution from Muto Pure Chemicals Co., Ltd. (Tokyo, Japan). The degree of liver fibrosis was assessed using Histoquest (Tissue Gnostics, Vienna, Austria) using the three 
images of each slide described above. The caudate liver lobes were embedded in Tissue-Tek OCT compound (Sakura Finetechnical Co., Ltd., Tokyo, Japan) and snapfrozen in liquid nitrogen. Frozen sections, $5 \mu \mathrm{m}$ thick, were fixed with $50 \%$ ethanol for $5 \mathrm{~min}$ and stained with Sudan III (Wako Pure Chemical Industries Ltd., Osaka, Japan) in $55 \%$ ethanol for $1.5 \mathrm{~h}$ at room temperature.

\section{X-ray computed tomography}

For the detection and characterization of tumor development, the mice were imaged using the in vivo threedimensional micro X-ray computed tomography (CT) system R-mCT2 (Rigaku, Tokyo, Japan). The X-ray tube voltage, current, and field of view were $90 \mathrm{kV}, 200 \mu \mathrm{A}$, and $30 \mathrm{~mm}$, respectively. ExiTron nano 6000 (Miltenyi Biotec, Bergisch Gladbach, Germany) was injected into the tail vein of the mice on the day before the CT scan at a dose of $10 \mathrm{~mL} / \mathrm{kg}$. ExiTron nano 6000 is uptake by Kupffer cells in liver, therefore, we defined the nodules which were not enhanced by ExiTron nano 6000. Using 512 CT image of samples, largest diameter of node and numbers were measured by Osirix software (OnDemand software, Cybermed Inc., Bernex, Switzerland).

\section{Comparison of HFCD + DEN and HFD32 + DEN}

High Fat Diet 32 (HFD32) was obtained from CLEA Japan, Inc. (Tokyo, Japan). This diet consists of $32.0 \%$ fat, $25.5 \%$ protein, $29.4 \%$ carbohydrate, and total calories of $507.6 \mathrm{kcal} / 100 \mathrm{~g}$. Five 3 -week-old male mice were fed HFD32 and received a one-time i.p. injection of $25 \mathrm{mg} / \mathrm{kg}$ DEN at the start of the feeding protocol. After 4 weeks, liver tissue was taken and snap-frozen in liquid nitrogen.

RNA was extracted from frozen liver tissue after 4 weeks of MF, HFCD + DEN, and HFD32 + DEN using the RNeasy Mini Kit (Qiagen, Hilden, Germany). Genome-wide mRNA expression levels were determined using the Superprint G3 Mouse GE microarray kit 8 x 60 k Ver 2.0, which contains 27,122 genes (G4858A\#074809, Agilent Technologies, South Queensferry, UK). All microarray data of the HFCD + DEN mice and HFD32 + DEN mice were normalized with data of the MF mice using GeneSpring GX Ver 13.1 software (Agilent Technologies); the threshold was set at more than twofold changes. We analyzed the data by means of Qiagen's Ingenuity Pathway Analysis (IPA) software Ver 1.0 (Qiagen, Hilden, Germany) for functional analysis. Molecules from the dataset that exceeded the twofold cutoff and were associated with biological function or diseases in the Ingenuity Knowledge Base were considered for analysis. The righttailed Fisher's exact test was used to calculate a $p$ value to determine the probability that each biological function or disease assigned to that dataset was due to chance alone.

\section{Statistical analysis}

The data are shown as the mean \pm standard deviation or number (\%). The Mann-Whitney $U$ test was used for the analysis of body and liver weight and ALT, TG, and leptin levels. We performed all statistical analyses using IBM SPSS Statistics 21 software (SPSS, Inc., Chicago, IL, USA).

\section{Results}

\section{Body weight, liver weight, and laboratory findings}

To develop the NASH-HCC model, we used a combination of an HFCD and i.p. DEN administration. The mice were divided into four groups: MF; HFCD; MF + DEN; and HFCD + DEN. Animals in the MF + DEN and HFCD + DEN groups received a single i.p. injection of DEN at the start of the respective feeding protocols. At 24 weeks, the mean body weights of the MF, HFCD, $\mathrm{MF}+\mathrm{DEN}$, and HFCD + DEN mice were $31.7 \mathrm{~g}, 54.5 \mathrm{~g}$, $32.6 \mathrm{~g}$, and $49.5 \mathrm{~g}$ (Fig. 2a), respectively; the mean liver weights were $1.2 \mathrm{~g}, 4.0 \mathrm{~g}, 1.3 \mathrm{~g}$, and $2.9 \mathrm{~g}$ (Fig. 2b), respectively. Both body weight and liver weight were significantly higher in the HFCD and HFCD + DEN groups than in the MF and MF + DEN groups.

Plasma ALT levels increased every 4 weeks, with the HFCD and HFCD + DEN groups showing remarkably high levels (Fig. 2c). Plasma TG levels peaked at 8 weeks for all four groups and decreased thereafter (Fig. 2d). There were significant differences in TG levels between the MF and HFCD + DEN groups at 16 and 20 weeks. Plasma leptin levels increased from 20 weeks in the HFCD and HFCD + DEN groups (Fig. 2e). Plasma adiponectin levels decreased from 20 weeks in the HFCD and HFCD + DEN groups (Fig. 2f).

The levels of other biomarkers, such as FBS, CRP, IL6, and TNF-alpha, are shown in Table 1. CRP levels increased from 20 weeks in the HFCD and HFCD + DEN groups, though there was no significant difference. However, compared with the MF group, serum levels of TNF-alpha were higher in the HFCD group at 4 and 8 weeks and in the HFCD + DEN group at 8 weeks. Serum levels of IL-6 tended to be higher in the HFCD and HFCD + DEN groups; however, at 16 weeks, only the HFCD group exhibited significantly different levels compared with the MF group.

\section{Insulin resistance}

Insulin resistance was calculated using the quantitative insulin sensitivity check index. All mice in the HFCD and HFCD + DEN groups had developed insulin resistance at 12 weeks, whereas animals in the MF and MF + DEN groups had developed insulin resistance at 24 weeks 

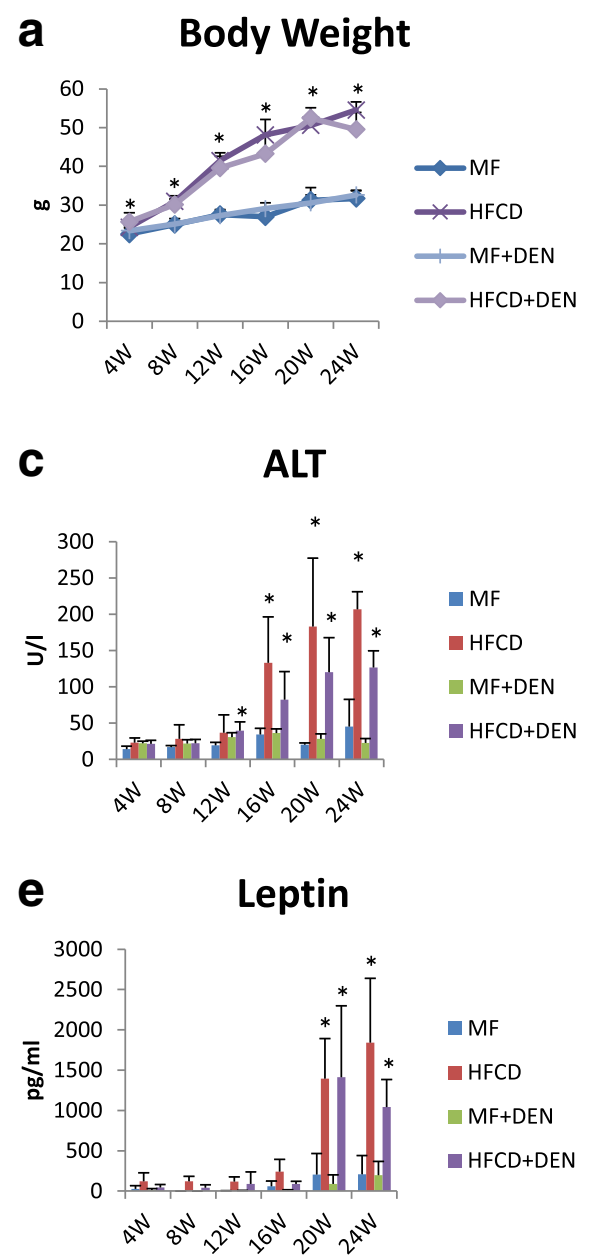

\section{b Liver Weight}

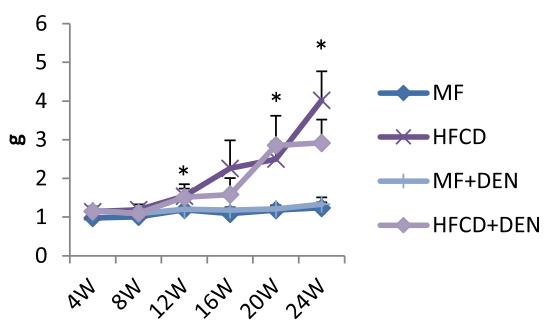

d

TG
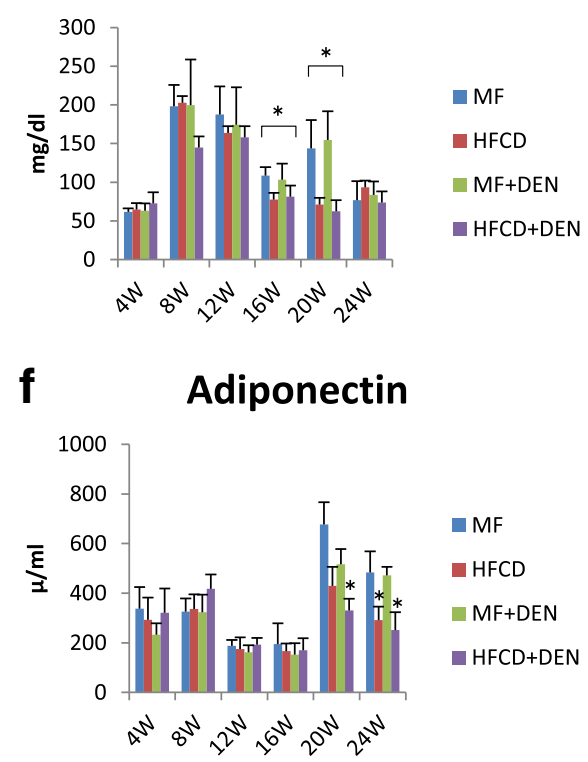

Fig. 2 Body and liver weights and laboratory findings: a body weight; $\mathbf{b}$ liver weight; c plasma alanine aminotransferase (ALT); d plasma triglycerides (TG); e plasma leptin; and $\mathbf{f}$ adiponectin. The data are shown as the mean + standard deviation. ${ }^{*} p<0.05$ indicates a significant difference between the standard diet (MF) group and the other groups for each month. HFCD, high-fat choline-deficient diet; DEN, diethylnitrosamine

(Table 2). To confirm the development of insulin resistance, we performed an insulin tolerance test. There was a significant difference in insulin resistance between the MF and HFCD + DEN groups at 80 and 100 min. There was also a significant difference in insulin resistance between the MF and HFCD groups at 80, 100, and 120 min (Fig. 3).

\section{Histological findings of non-tumor tissue}

Liver specimens were evaluated using hematoxylin-eosin staining. At 12 weeks, mice in the HFCD and HFCD + DEN groups evidenced fat accumulation, lobular inflammation, and hepatocyte ballooning, which are characteristic of NASH. These changes were more evident in specimens from the HFCD + DEN group than in those from the HFCD group (Fig. 4a). We observed no apparent pathological findings, including fatty degeneration or necroinflammatory changes in hepatocytes in the hematoxylin-eosin-stained tissue of MF or MF +
DEN mice. Sudan III staining revealed remarkable macrovesicular fat accumulation in both the HFCD and HFCD + DEN groups at 12 weeks; microvesicular fat accumulation was evident in the MF group-and to a lesser extent in the MF + DEN group (Fig. 4b). Lipogranuloma (Fig. 4c), Mallory-Denk bodies (Fig. 4d), and hepatocyte ballooning (Fig. 4e), which are characteristic of NASH, were observed in the HFCD + DEN mice from 16 weeks after feeding.

NAS is an established scoring system for assessing the severity of NASH. In the NAS system, a score of 3-5 represents possible or borderline NASH; a score greater than 5 indicates definite NASH. The NAS was possible or borderline from 16 weeks and definite from 20 weeks in the HFCD mice; it was possible or borderline from 12 weeks and definite from 16 weeks in the HFCD + DEN group (Table 3).

To evaluate inflammation, we undertook immunohistochemical detection of macrophages with F4/80 antibody 
Table 1 Summary of laboratory findings for FBS, CRP, IL-6, TNF-alpha, and adiponectin levels

\begin{tabular}{|c|c|c|c|c|c|}
\hline & Week & MF & HFCD & $\mathrm{MF}+\mathrm{DEN}$ & $\mathrm{HFCD}+\mathrm{DEN}$ \\
\hline \multirow[t]{6}{*}{ FBS (mg/dl) } & 4 & $211.3 \pm 41.7$ & $297.5 \pm 24.6$ & $191.0 \pm 11.2$ & $282.3 \pm 26.5$ \\
\hline & 8 & $149.6 \pm 30.9$ & $174.2 \pm 32.9$ & $177.0 \pm 64.9$ & $167.6 \pm 31.3$ \\
\hline & 12 & $167.6 \pm 41.6$ & $241.6 \pm 32.4$ & $152.0 \pm 24.2$ & $273.4 \pm 31.5$ \\
\hline & 16 & $109.8 \pm 11.4$ & $245.0 \pm 46.4$ & $112.8 \pm 8.7$ & $189.8 \pm 52.5$ \\
\hline & 20 & $188.4 \pm 14.6$ & $263.2 \pm 36.0$ & $172.0 \pm 36.7$ & $242.0 \pm 14.4$ \\
\hline & 24 & $165.2 \pm 23.9$ & $265.2 \pm 6.5$ & $205.3 \pm 32.5$ & $249.4 \pm 24.2$ \\
\hline \multirow[t]{6}{*}{ CRP (ng/ml) } & 4 & $4552.6 \pm 2533.3$ & $3756.8 \pm 1366.4$ & $4284.9 \pm 2261.0$ & $4915.4 \pm 1697.0$ \\
\hline & 8 & $5803.1 \pm 1368.7$ & $13324.9 \pm 7100.6$ & $5837.7 \pm 2422.0$ & $6568.3 \pm 3827.0$ \\
\hline & 12 & $2412.0 \pm 211.8$ & $2505.3 \pm 517.7$ & $2465.9 \pm 170.5$ & $2427.1 \pm 337.3$ \\
\hline & 16 & $2080.4 \pm 756.5$ & $3065.7 \pm 1047.4$ & $2801.3 \pm 457.0$ & $3002.1 \pm 599.5$ \\
\hline & 20 & $2125.1 \pm 306.9$ & $3170.3 \pm 711.8$ & $2185.4 \pm 256.3$ & $3293.4 \pm 416.6$ \\
\hline & 24 & $2227.6 \pm 613.8$ & $3143.3 \pm 393.3$ & $2044.0 \pm 349.9$ & $3686,7 \pm 481.2$ \\
\hline \multirow[t]{6}{*}{ IL-6 (pg/ml) } & 4 & $0.2 \pm 0.3$ & $1.3 \pm 1.5$ & $0.3 \pm 0.5$ & $0.9 \pm 1.3$ \\
\hline & 8 & $0.5 \pm 0.5$ & $1.8 \pm 1.5$ & $0.6 \pm 0.7$ & $0.9 \pm 1.2$ \\
\hline & 12 & $0.8 \pm 0.5$ & $1.1 \pm 0.7$ & $1.1 \pm 0.8$ & $2.0 \pm 1.5$ \\
\hline & 16 & $1.3 \pm 0.6$ & $2.9 \pm 1.2$ & $1.2 \pm 0.8$ & $0.9 \pm 0.2$ \\
\hline & 20 & $1.6 \pm 1.2$ & $1.3 \pm 0.8$ & $1.4 \pm 0.9$ & $1.6 \pm 0.9$ \\
\hline & 24 & $2.1 \pm 1.3$ & $4.2 \pm 1.8$ & $2.2 \pm 4.5$ & $1.6 \pm 0.3$ \\
\hline \multirow[t]{6}{*}{ TNF-alpha (pg/ml) } & 4 & N.D. & $20.7 \pm 28.9$ & N.D. & $6.2 \pm 12.0$ \\
\hline & 8 & $1.8 \pm 3.9$ & $270.9 \pm 297.5$ & $5.0 \pm 7.1$ & $134.6 \pm 153.7$ \\
\hline & 12 & $2.2 \pm 2.8$ & $0.4 \pm 0.9$ & $0.9 \pm 2.0$ & $1.9 \pm 3.1$ \\
\hline & 16 & $0.1 \pm 0.1$ & $3.4 \pm 4.8$ & $0.1 \pm 0.3$ & N.D. \\
\hline & 20 & $1.2 \pm 1.6$ & $2.0 \pm 2.2$ & $1.4 \pm 1.4$ & $1.4 \pm 1.3$ \\
\hline & 24 & $3.8 \pm 6.4$ & $5.8 \pm 3.0$ & $3.5 \pm 5.2$ & $0.5 \pm 1.2$ \\
\hline
\end{tabular}

The data are shown as the mean \pm standard deviation. Each group contained five mice. FBS fasting blood sugar, CRP C-reactive protein, IL interleukin, TNF-alpha tumor necrosis factor-alpha

and SAA measurement. Representative images of macrophages in the perivenular zone at 4 weeks in the MF and HFCD + DEN mice are presented in Fig. 5a, b. The ratio of F4/80-positive cells (macrophages) to hepatocyte nuclei was higher in the HFCD and HFCD + DEN groups than in the other two groups from 4 weeks (Fig. 5c). SAA was significantly higher after 20 weeks in the HFCD + DEN mice and at 24 weeks in the HFCD mice (Fig. 5d). Fibrosis was more conspicuous in the HFCD and HFCD + DEN mice than in the other two groups (Fig. 5e). The area of fibrosis increased dramatically from 12 weeks in the HFCD + DEN mice and from 16 weeks in the HFCD group (Fig. 5f).

\section{CT scans and immunohistochemistry of hepatic tumors}

To evaluate tumor development, we performed a CT scan every 4 weeks from week 12 . The largest liver mass had a maximum diameter of $13 \mathrm{~mm}$ at 24 weeks in the HFCD + DEN group (Fig. 6a, b). Small nodules were typically seen in the liver macroscopically and by CT scan at 24 weeks (Fig. 6c-e). Positive findings were evident in $20 \%$ and $100 \%$ of the HFCD + DEN mice at 16 weeks and 20 weeks, respectively. Only one mouse had positive findings in the HFCD group at 20 weeks and one mouse in the $\mathrm{MF}+\mathrm{DEN}$ group at 24 weeks. In the HFCD + DEN group, there were on average eight tumors at 24 weeks, with an average size of $2.9 \mathrm{~mm}$ (Table 4). To confirm malignancy, we immunostained the tumors to detect GS. GS-positive HCC was found in some specimens (Fig. 6f, g), although not all tumors were stained.

\section{Comparison of HFCD + DEN and HFD32 + DEN}

To determine why HFCD + DEN promoted cancer development, we performed RNA microarray analysis. For this, we used HFD32, which is a widely employed highfat diet. Principal component analysis provides a way of identifying predominant gene expression patterns. Surprisingly, the general expression of HFCD + DEN was closer to MF than to HFD32 + DEN (Fig. 7a). Clustering analysis and gene ontology analysis indicated that 
Table 2 Insulin resistance calculated using the quantitative insulin sensitivity check index

\begin{tabular}{lllllll}
\hline & $4 W$ & $8 W$ & 12 W & 16 W & 20 W & 24 W \\
\hline MF & N.D. & $\mathbf{0 . 2 2 7}$ & $\mathbf{0 . 1 3 9}$ & N.D. & N.D. & 0.413 \\
& $\mathbf{0 . 0 6 4}$ & N.D. & 0.348 & N.D. & 0.445 & $\mathbf{0 . 1 2}$ \\
N.D. & 0.381 & $\mathbf{0 . 1 9 3}$ & N.D. & N.D. & $\mathbf{0 . 2 4 9}$ \\
& N.D. & N.D. & 0.416 & 0.315 & N.D. & 0.777 \\
HFCD & N.D. & N.D. & 0.672 & N.D. & N.D. & $\mathbf{0 . 0 8 3}$ \\
& N.D. & $\mathbf{0 . 2 2}$ & $\mathbf{0 . 0 8 9}$ & $\mathbf{0 . 0 5 8}$ & $\mathbf{0 . 0 2 6}$ & $\mathbf{0 . 0 4 5}$ \\
& $\mathbf{0 . 2 0 0 2}$ & $\mathbf{0 . 2 0 6}$ & $\mathbf{0 . 0 4 7}$ & $\mathbf{0 . 0 3 4}$ & $\mathbf{0 . 0 2 6}$ & $\mathbf{0 . 0 2 5}$ \\
& 0.3954 & $\mathbf{0 . 1 6 8}$ & $\mathbf{0 . 0 6 7}$ & $\mathbf{0 . 0 3 4}$ & $\mathbf{0 . 0 5 7}$ & $\mathbf{0 . 0 2 5}$ \\
& $\mathbf{0 . 0 7 0 5}$ & N.D. & $\mathbf{0 . 0 8 1}$ & $\mathbf{0 . 0 2 7}$ & $\mathbf{0 . 0 3 4}$ & $\mathbf{0 . 0 1 8}$ \\
& $\mathbf{0 . 1 3 8 4}$ & N.D. & $\mathbf{0 . 0 4 6}$ & $\mathbf{0 . 0 7 9}$ & $\mathbf{0 . 0 3 7}$ & $\mathbf{0 . 0 3 0}$ \\
& 1.047 & N.D. & 0.579 & N.D. & N.D. & $\mathbf{0 . 2 9 1 6}$ \\
& N.D. & N.D. & N.D. & N.D. & N.D. & $\mathbf{0 . 1 1 6}$ \\
& N.D. & 0.916 & N.D. & 0.642 & N.D. & $\mathbf{0 . 1 3 1}$ \\
& N.D. & 0.916 & N.D. & N.D. & N.D. & $\mathbf{0 . 1 5 3}$ \\
& N.D. & 0.159 & N.D. & 9.101 & $\mathbf{0 . 2 4 5}$ & N.D. \\
\hline HFCD + DEN & 1.047 & $\mathbf{0 . 0 8 0 8}$ & $\mathbf{0 . 0 1 6}$ & $\mathbf{0 . 0 7 2}$ & $\mathbf{0 . 0 3 3}$ & $\mathbf{0 . 0 2 6}$ \\
& N.D. & $\mathbf{0 . 1 1 6 7}$ & $\mathbf{0 . 0 3 1}$ & $\mathbf{0 . 0 5 4}$ & $\mathbf{0 . 0 6 3}$ & $\mathbf{0 . 0 2 0}$ \\
& $\mathbf{0 . 1 0 2 6}$ & 0.377 & $\mathbf{0 . 0 3 0}$ & $\mathbf{0 . 0 2 5}$ & $\mathbf{0 . 0 6 9}$ & $\mathbf{0 . 0 3 4}$ \\
& $\mathbf{0 . 0 8 2 6}$ & 0.315 & $\mathbf{0 . 0 4 8}$ & 0.314 & $\mathbf{0 . 2 0 1}$ & $\mathbf{0 . 0 3 1}$ \\
& $\mathbf{0 . 1 7 2}$ & $\mathbf{0 . 1 7 3}$ & $\mathbf{0 . 0 3 6}$ & $\mathbf{0 . 0 2 2}$ & $\mathbf{0 . 0 5 5}$ & $\mathbf{0 . 0 3 7}$ \\
\hline
\end{tabular}

The quantitative insulin sensitivity check index $=1 / \log$ (fasting insulin) + log (fasting glucose). A value $<0.3$ indicates insulin resistance; values from 0.348 to 0.430 are normal, and values $\geq 3.0$ indicate high insulin sensitivity (type 1 diabetes mellitus). Index values $<0.3$ (insulin resistance) are in bold. Each group contained five mice. $W$ weeks, MF standard diet, HFCD high-fat choline-deficient diet, DEN diethylnitrosamine, N.D not determined probably as a result of hepatitis, HFCD + DEN and HFD32 commonly changed the expression gene related to defense response and immune response. Functional analysis extracted 13 genes from HFCD + DEN and 163 from HFD32 + DEN related to HCC: HFCD + DEN and HFD32 + DEN were found to have six genes in common. As seen in the heat map in Fig. $7 \mathrm{~b}$ and Additional file 1, expression of Histone cluster 1, H3c (Hist1h3c), histone cluster 1, H3g (Hist1h3g), Mitochondrial transcription termination factor 2 (Mterf2), ArfGAP with SH3 domain, ankyrin repeat and $\mathrm{PH}$ domain 2 (Asap2), and Hair growth associated $(\mathrm{Hr})$ showed an increase in both the HFCD + DEN and HFD32 + DEN groups. Expression of Retinoblastoma binding protein 6 (Rbbp6) in HFCD + DEN presented a slight decrease, though it was a large decrease in HFD32 + DEN.

\section{Discussion}

It has been reported that the development and progression of NASH-HCC follows a multiple-hit pathway, which includes metabolic syndrome, genetic factors, oxidative stress, inflammatory cytokine release, endotoxins, and insulin resistance [5]. Previous NASH models have combined two or more of these hits by using a special diet with a chemical agent [21, 27] or specific genetic changes $[14,20]$. However, these demand relatively long periods before the onset of HCC. NASH models based only on an HFCD require considerably longer periods-usually more than 1 year-to reliably produce carcinoma [17]. By combining an HFCD with a chemical agent, DEN, our model resulted in

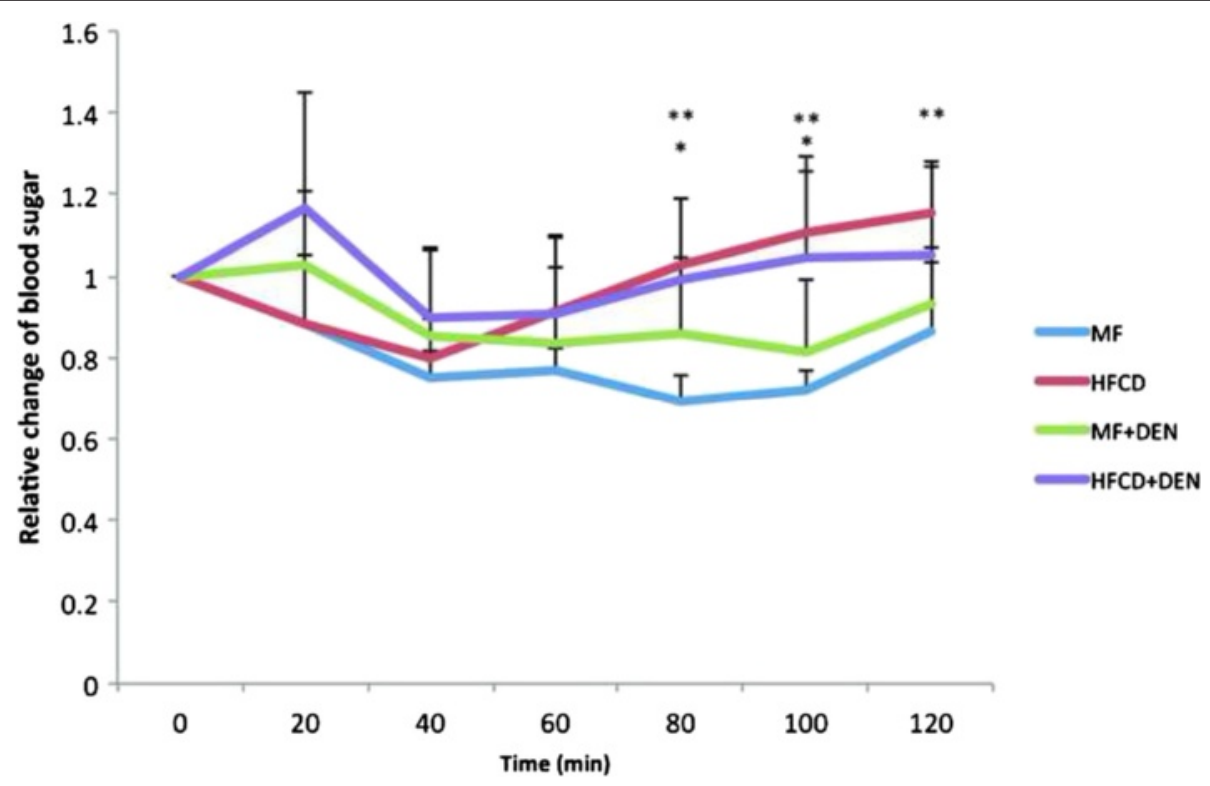

Fig. 3 Insulin tolerance test at 12 weeks. The data appear as the mean + standard deviation. ${ }^{*} p<0.05$ indicates a significant difference between the standard diet (MF) group and the high-fat, choline-deficient diet (HFCD) + diethylnitrosamine (DEN) group. ${ }^{* *} p<0.05$ indicates a significant difference between the MF and HFCD groups 


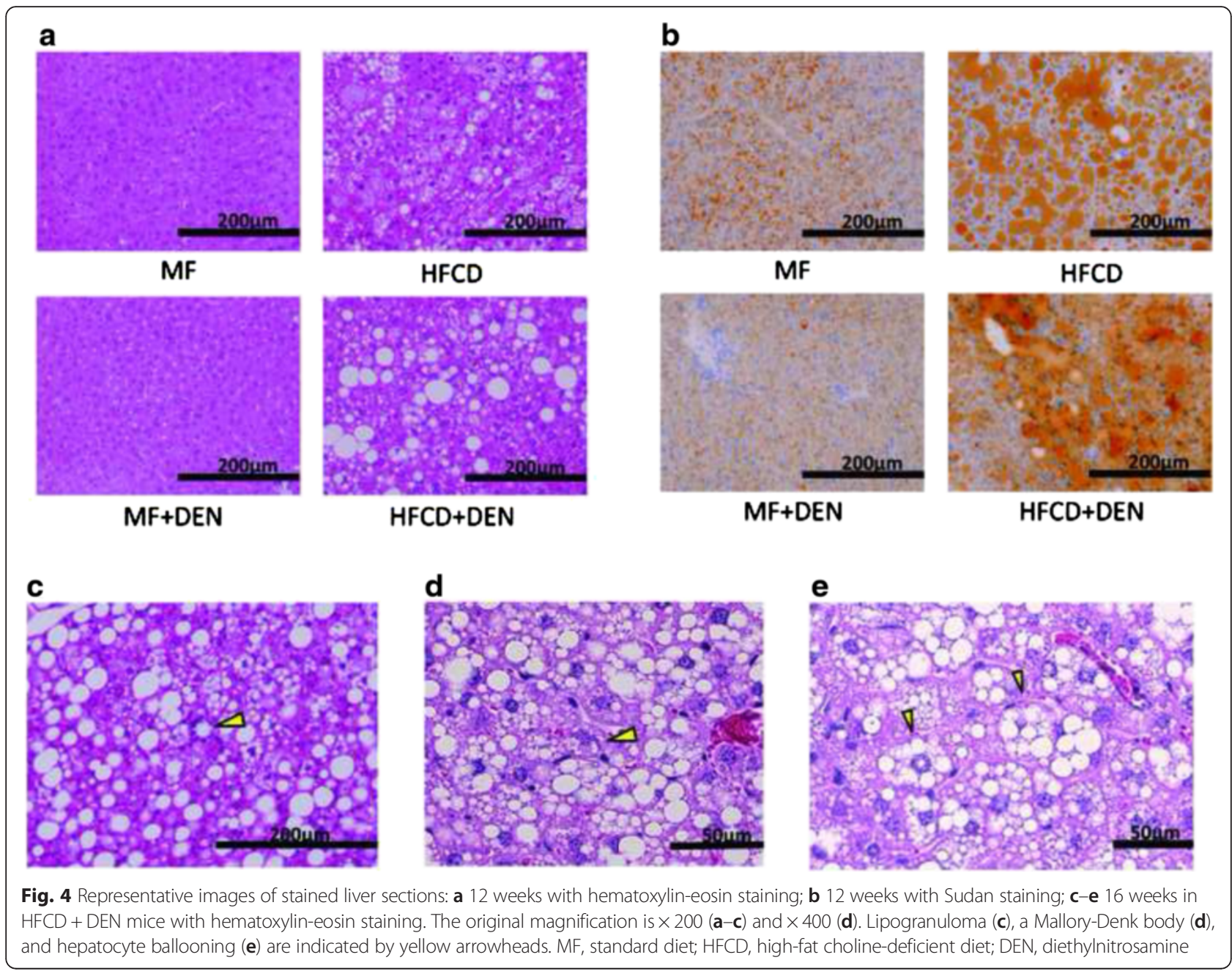

carcinoma within 20 weeks. DEN increases oxidative stress [31], which is one of the most important factors in the development and progression of NASH since it stimulates Kupffer cells [32]. Mice in the HFCD + DEN group showed elevated SAA levels, a higher NAS, and earlier fibrosis than those in the HFCD group. We also demonstrated that our NASH mouse model-based on an HFCD

Table 3 Nonalcoholic fatty liver disease activity score (NAS)

\begin{tabular}{llllll}
\hline & Week & MF & HFCD & MF + DEN & HFCD + DEN \\
\hline NAS & 4 & 0 & $0.6 \pm 0.9$ & $0.6 \pm 0.6$ & $1.3 \pm 0.5$ \\
& 8 & 0 & $0.8 \pm 0.8$ & $0.4 \pm 0.6$ & $1.2 \pm 1.6$ \\
12 & 0 & $2.6 \pm 1.7$ & $1 \pm 0$ & $3 \pm 2.0$ \\
16 & $0.2 \pm 0.5$ & $4.6 \pm 2.2$ & $1 \pm 0$ & $5.2 \pm 1.3$ \\
20 & 0 & $5.2 \pm 0.5$ & $1 \pm 0$ & $5.4 \pm 0.6$ \\
24 & 0 & $6.2 \pm 0.8$ & $1 \pm 0$ & $5.6 \pm 0.6$ \\
\hline
\end{tabular}

Each group contained five mice. MF standard diet, HFCD high-fat cholinedeficient diet, $D E N$ diethylnitrosamine combined with i.p. injection of DEN-stimulated insulin resistance, fibrosis, and HCC within 20 weeks (Fig. 8).

The MCD model is one of the best-known NASH animal models $[19,20]$. Choline deficiency causes Cyp2E1 upregulation with increased reactive oxygen species formation, lipid peroxidation, and mitochondrial dysfunction [27]; methionine deficiency exacerbates hepatic injury associated with oxidative and endoplasmic reticulum stress [33]. Although MCD mice develop steatohepatitis, fibrosis, and carcinogenesis, both body weight and insulin resistance tend to decrease because of reduced food intake and increased basal metabolism. The MCD model thus reflects a different pathophysiology than human NASH with respect to metabolic syndrome.

Few reported NASH-HCC models have fully incorporated all the clinical changes associated with that disease [28-30]. In our HFCD + DEN model, tumor initiation is basically dependent on a chemical carcinogen, which is artificial compared with the above spontaneous HCC 
a

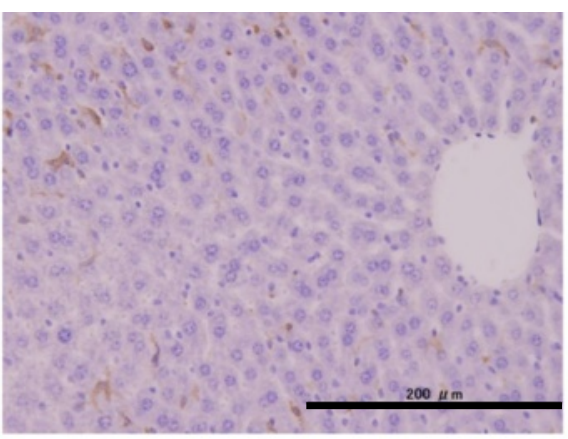

F4/80 stain, MF group

C

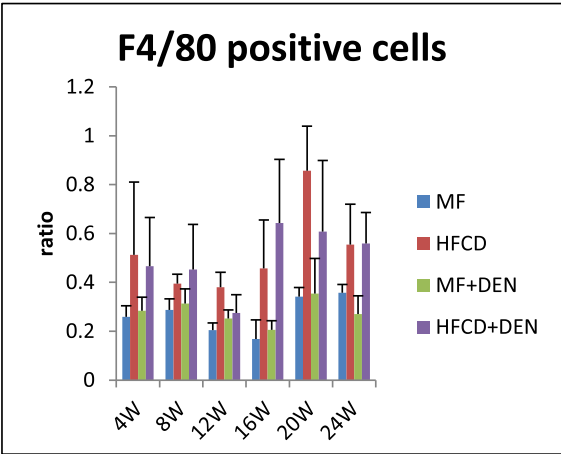

e

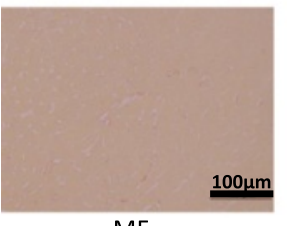

MF

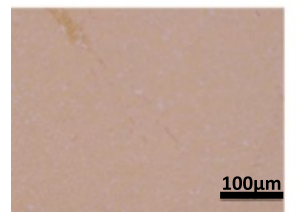

$M F+D E N$

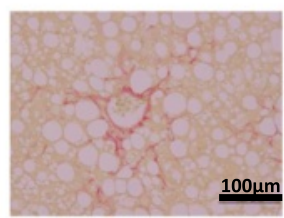

HFCD

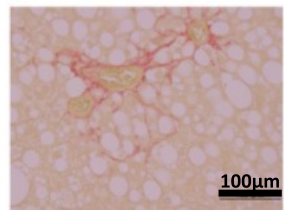

HFCD+DEN b

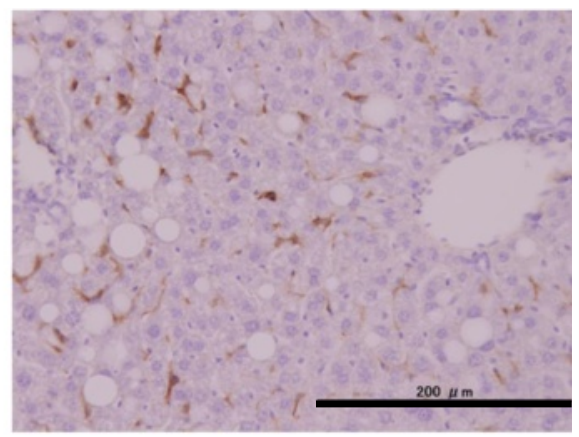

d

$F 4 / 80$ stain, $H F C D+D E N$ group

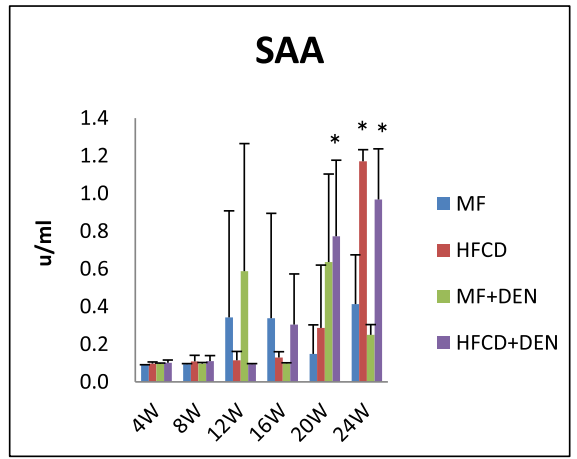

f

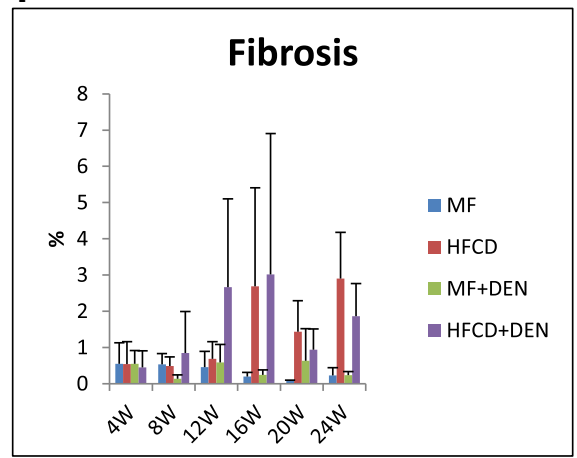

Fig. 5 Immunohistochemistry with F4/80 antibody ( $\times 200$ original magnification) at 4 weeks: a standard diet (MF) group; b high-fat, cholinedeficient diet (HFCD) + diethylnitrosamine (DEN) group; $\mathbf{c}$ the ratio of F4/80-positive cells (macrophages) to hepatocyte nuclei; $\mathbf{d}$ serum amyloid $\mathrm{A}$ (SAA) immunostaining; e representative images of liver sections stained with Sirius red at 24 weeks; and $\mathbf{f}$ proportion of fibrotic area measured using Histoquest. The data are shown as the mean + standard deviation

models. Thus, the HFCD + DEN model cannot assess the initiation step of NASH-HCC. However, the time to HCC development in our HFCD + DEN model is 20 weeks. This is the shortest among comparable models-the high-fat and fructose diet model, MUP-uPA transgenic mice with HFD, and MC4R knockout mice with HFD, which have 48,32 , and 48 weeks, respectively. Therefore, the HFCD + DEN model may be appropriate to assess how the NASH environment promotes HCC.

Our functional analysis extracted 13 genes from HFCD + DEN and 163 from HFD32 + DEN related to
HCC. Expression of Rbbp6 in HFCD + DEN and HFD32 + DEN decreased (Fig. 7b). Rbbp6 is known to interact with MDM2, and it enhanced the affinity of MDM2 for p53, which led to the ubiquitination and degradation of p53 and repression of p53-dependent gene transcription. It would be interesting to explore in detail the differences in the cancer development mechanisms among those models. One limitation with this analysis is that the samples covered only a 4-week duration. We were thus unable to observe the long-term effects of gene expression. Further investigation is required to clarify this matter. 

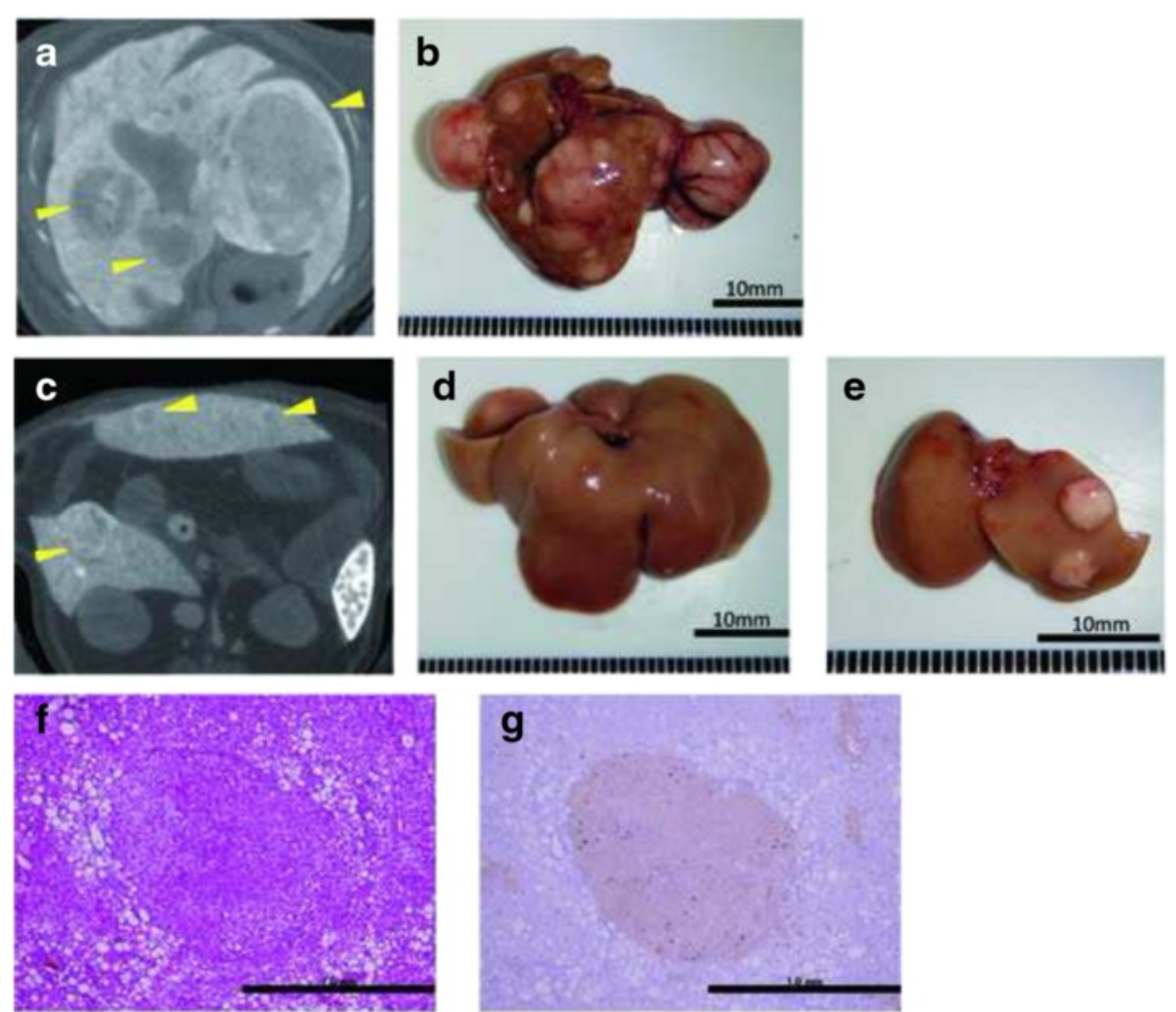

Fig. 6 Computed tomography scans and immunohistochemistry of hepatic tumors in the high-fat, choline-deficient (HFCD) + diethylnitrosamine (DEN) group at 24 weeks: a, c computed tomography findings; b-e macroscopic views. The image in $\mathbf{a}$ is a section of the whole liver depicted in $\mathbf{b}$; the image in $\mathbf{c}$ is a section of the whole liver shown in $\mathbf{d}$; and the image in panel e depicts the right and left medial lobes of the whole liver in panel $\mathbf{d}$. The lesions are indicated by yellow arrowheads. $\mathbf{f}$ Hematoxylin-eosin staining of the liver tumor. $\mathbf{g}$ Immunohistochemical staining for glutamine synthetase

Table 4 Summary of computed tomography findings, rate of positive findings, tumor number, and tumor size from 12 to 24 weeks

\begin{tabular}{|c|c|c|c|c|c|}
\hline & Week & MF & HFCD & MF + DEN & $\mathrm{HFCD}+\mathrm{DEN}$ \\
\hline \multirow[t]{4}{*}{ Mice with positive findings, $\mathrm{n}(\%)$} & 12 & 0 & 0 & 0 & 0 \\
\hline & 16 & 0 & 0 & 0 & $1 / 5(20 \%)$ \\
\hline & 20 & 0 & $1 / 5(20 \%)$ & 0 & $5 / 5(100 \%)$ \\
\hline & 24 & 0 & 0 & $1 / 5(20 \%)$ & $5 / 5(100 \%)$ \\
\hline \multirow[t]{4}{*}{ Tumor number } & 12 & 0 & 0 & 0 & 0 \\
\hline & 16 & 0 & 0 & 0 & 5 \\
\hline & 20 & 0 & 6 & 0 & $10.0 \pm 5.4$ \\
\hline & 24 & 0 & 0 & 1 & $8.8 \pm 5.4$ \\
\hline \multirow[t]{4}{*}{ Tumor size (mm) } & 12 & & & & \\
\hline & 16 & & & & $0.6 \pm 0.4$ \\
\hline & 20 & & $0.8 \pm 0.2$ & & $1.6 \pm 0.8$ \\
\hline & 24 & & & 2.2 & $2.9 \pm 2.8$ \\
\hline
\end{tabular}

Data are shown as the mean \pm standard deviation. Data in bold indicate a significant difference $(p<0.05)$ between the standard diet (MF) group and the other groups for each month. HFCD high-fat choline-deficient diet, DEN diethylnitrosamine 

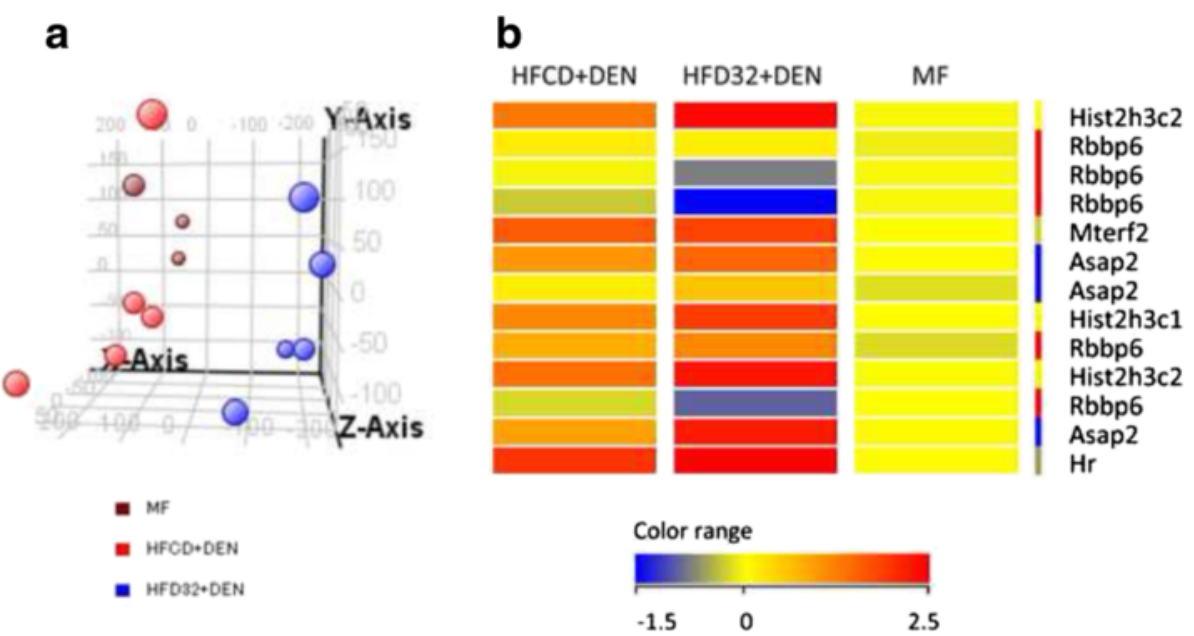

Fig. 7 Expression of MF, HFCD + DEN, and HFD32. a Principal component analysis of MF (brawn), HFCD + DEN (red), and HFD32 + DEN (blue). MF group contained three mice. HFCD + DEN and HFD32 + DEN group contained five mice. $\mathbf{b}$ Heat map of HCC-related genes common to both HFCD + DEN and HFD32 + DEN. DEN, diethylnitrosamine; standard diet (MF); HFCD, high-fat, choline-deficient diet; HFD32, high-fat diet

Insulin resistance is another essential feature of $\mathrm{NASH}$, which is a hepatic manifestation of metabolic syndrome [34], and insulin resistance plays an important role in exacerbation of NASH. A number of NASH models with diabetes mellitus, such as the KK- $\mathrm{A}^{\mathrm{y}}$ mouse on the MCD diet and mice fed an HFD combined with STZ, have been reported $[20,21]$. The $\mathrm{KK}-\mathrm{A}^{\mathrm{y}}$ mouse is a genetically engineered diabetes mellitus model with insulin resistance, but it is unclear whether it exhibits carcinogenesis. STZ destroys the insulin-producing beta cells of the pancreas; therefore, mice receiving STZ develop type 1 diabetes mellitus owing to a lack of insulin secretion rather than through the de novo development of insulin resistance. In our study, most mice exhibited insulin resistance after 12 weeks (Table 2, Fig. 3).

Although a few mice in our model developed liver cirrhosis, we believe this model will be beneficial for studying NASH-HCC. Clinically, it is unclear whether cirrhosis is a prerequisite for the development of $\mathrm{HCC}$ in patients with NASH. Cirrhosis and advanced fibrosis appear to be the predominant risk factors for $\mathrm{HCC}$ development; however, $28 \%$ of NASH-associated HCC cases have less advanced forms of fibrosis (stage 1 or 2), and fibrosis is more frequent in men [7].

Based on CT findings, all mice in the HFCD + DEN group, but no animals in the HFCD group, had liver tumors at 20 weeks (Table 4). Histologically, focal nodular hyperplasia and dysplasia were also present. Consistent with these findings, our immunohistochemistry results showed both GS-positive HCC (Fig. 6g) and GS-negative tumors.

Leptin is a peptide hormone produced by adipocytes and is involved in appetite control and energy expenditure [35]. Obese patients often have leptin resistance and high serum levels of leptin, which exacerbate obesity and hypertension owing to a sustained increase in sympathetic nerve activity. Hyperleptinemia is also related to hyper-responsiveness to low-dose endotoxin, which is

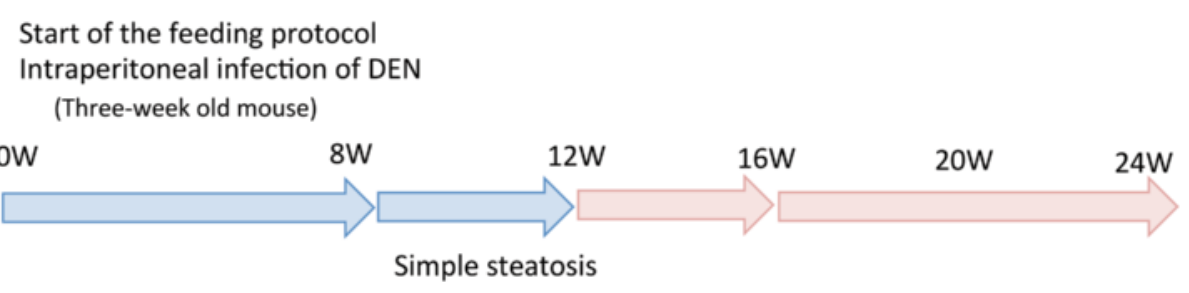

NASH, fibrosis

HCC development Hepatocyte ballooning Mallory-Denk body Lipogranuloma

Fig. 8 Summary of the experimental model. DEN, diethylnitrosamine; HCC, hepatocellular carcinoma; NASH, nonalcoholic steatohepatitis 
associated with NASH progression [36]. The mice in our model developed hyperleptinemia (Fig. 2e) and hypoadiponectinemia (Fig. 2f) after 20 weeks. Park et al. have reported that feeding HFD to DEN-treated mice promotes HCC development through TNF and IL-6 expression [37]. Serum levels of TNF-alpha were higher in the HFCD and HFCD + DEN groups than in the MF group at 4 and 8 weeks; however, this difference was not significant owing to large individual differences within each group (Table 1). Our findings appear to be consistent with those of another report, which found the adipocytokine level to be highest at 8 weeks and gradually decreased thereafter [21]. Although, the reason for this is unknown, serum levels of TNF-alpha and IL-6 after 12 weeks were not particularly high compared with those in the MF group.

Wolf et al. recently reported that long-term feeding an HFCD diet to mice can induce HCC, which depends on intrahepatic CD8+ T cells and NKT cells [38]. In our microarray analysis results, many genes known to affect the immune response exceeded the twofold cutoff.

A mouse model that bears the same clinical features as human NASH-HCC can be used for research into the treatment and chemoprevention of $\mathrm{HCC}$ resulting from $\mathrm{NASH}$. One advantage of a mouse model is that a smaller drug amount is needed than with a rat model. Mice also have shorter generation times than rats. They are thus an efficient model for appropriate research by drug therapies. The most important advantage of a murine model is the anatomical and genetic similarity of mice to humans.

\section{Conclusion}

The NASH-HCC model we describe here is simple to establish, results in rapid tumor formation, and recapitulates most of the key features of NASH. It could therefore facilitate further studies into the development, oncogenic potential, diagnosis, and treatment of this condition.

\section{Additional file}

Additional file 1: Gene symbol, probe name and data form microarray analysis, and probe name and sequence for microarray analysis. (DOCX $20 \mathrm{~kb})$

\section{Abbreviations}

ALT, alanine aminotransferase; CRP, C-reactive protein; $C T$, computed tomography; DEN, diethylnitrosamine; FBS, fasting blood sugar; GS, glutamine synthetase; HCC, hepatocellular carcinoma; HFCD, high-fat, choline-deficient diet; HFD, high-fat diet; IL, interleukin; i.p, intraperitoneal; MCD, methionine- and choline-deficient diet; MF, standard diet; NAFLD, nonalcoholic fatty liver disease; NAS, NAFLD activity score; NASH, nonalcoholic steatohepatitis; SAA, serum amyloid A; TG, triglyceride; TNF, tumor necrosis factor

\section{Acknowledgements}

The authors thank Ms. Y. Nakamura, Ms. M. Matsuda, Ms. S. Matsuda, Ms. Y. Takagi, and Dr. S. Akimoto for their continued technical support. We are grateful to the Collaborative Research Resources, School of Medicine, Keio University for technical support and reagents.

\section{Funding}

This work was supported by a Grant-in Aid of Scientific Research C from Japan and Chugai Pharmaceutical as Endowed Research Chair.

\section{Availability of data materials}

The datasets supporting the conclusions of this article are included within the article.

\section{Authors' contributions}

NK conceived, designed, and performed the experiments, analyzed the data, and wrote the manuscript. SM conceived, designed, and performed the experiments, analyzed the data, and wrote the manuscript. Ol conceived, designed, and performed the experiments, analyzed the data, and wrote the manuscript. MS analyzed the data. MK analyzed the data. HY analyzed the data. YA analyzed the data. TH analyzed the data. YM analyzed the data. MS analyzed the data. YK contributed reagents, materials, and analytical tools. KA contributed reagents, materials, and analytical tools. All authors read and approved the final version of the manuscript.

\section{Competing interests}

The authors have no potential conflicts of interest to disclose.

\section{Consent for publication}

Not applicable.

\section{Ethics approval and consent to participate}

This study was approved by the Keio University Institutional Animal Care and Use Committee (Approval number: 08073).

\section{Author details}

'Department of Surgery, School of Medicine, Keio University, 35 Shinanomachi, Shinjuku-ku, Tokyo 160-8582, Japan. ${ }^{2}$ Chugai Pharmaceutical Endowed Research Chair in Molecular Targeted Therapy of Gastrointestinal Cancer, School of Medicine, Keio University, Tokyo, Japan. ${ }^{3}$ Department of Pathology, School of Medicine, Keio University, Tokyo, Japan. ${ }^{4}$ Department of Surgery, Kawasaki Municipal Hospital, Kawasaki-ku, Japan.

Received: 3 September 2015 Accepted: 1 June 2016

Published online: 13 June 2016

\section{References}

1. El-Serag HB. Hepatocellular carcinoma. N Engl J Med. 2011;365:1118-27.

2. Amarapurkar DN, Hashimoto E, Lesmana LA, Sollano JD, Chen PJ, Goh KL. How common is non-alcoholic fatty liver disease in the Asia-Pacific region and are there local differences? J Gastroenterol Hepatol. 2007;22:788-93.

3. Chitturi S, Farrell GC, Hashimoto E, Saibara T, Lau GK, Sollano JD. Nonalcoholic fatty liver disease in the Asia-Pacific region: definitions and overview of proposed guidelines. J Gastroenterol Hepatol. 2007;22:778-87.

4. Yasui K, Hashimoto E, Tokushige K, Koike K, Shima T, Kanbara Y, et al. Clinical and pathological progression of non-alcoholic steatohepatitis to hepatocellular carcinoma. Hepatol Res. 2012:42:767-73.

5. Polyzos SA, Kountouras J, Zavos C, Deretzi G. Nonalcoholic fatty liver disease: multimodal treatment options for a pathogenetically multiple-hit disease. J Clin Gastroenterol. 2012;46:272-84.

6. Okanoue T, Umemura A, Yasui K, Itoh Y. Nonalcoholic fatty liver disease and nonalcoholic steatohepatitis in Japan. J Gastroenterol Hepatol. 2011;26 Suppl 1:153-62.

7. Yasui K, Hashimoto E, Komorizono Y, Koike K, Arii S, Imai Y, et al. Characteristics of patients with nonalcoholic steatohepatitis who develop hepatocellular carcinoma. Clin Gastroenterol Hepatol. 2011:9:428-33. quiz e450.

8. Hashimoto E, Yatsuji S, Tobari M, Taniai M, Torii N, Tokushige K, et al. Hepatocellular carcinoma in patients with nonalcoholic steatohepatitis. J Gastroenterol. 2009;44 Suppl 19:89-95.

9. Yatsuji S, Hashimoto E, Tobari M, Taniai M, Tokushige K, Shiratori K. Clinical features and outcomes of cirrhosis due to non-alcoholic 
steatohepatitis compared with cirrhosis caused by chronic hepatitis C. J Gastroenterol Hepatol. 2009;24:248-54.

10. Shimada M, Hashimoto E, Taniai M, Hasegawa K, Okuda H, Hayashi N, et al. Hepatocellular carcinoma in patients with non-alcoholic steatohepatitis. J Hepatol. 2002;37:154-60.

11. Marrero JA, Fontana RJ, Su GL, Conjeevaram HS, Emick DM, Lok AS. NAFLD may be a common underlying liver disease in patients with hepatocellular carcinoma in the United States. Hepatology. 2002;36:1349-54.

12. Bugianesi E, Leone N, Vanni E, Marchesini G, Brunello F, Carucci P, et al. Expanding the natural history of nonalcoholic steatohepatitis: from cryptogenic cirrhosis to hepatocellular carcinoma. Gastroenterology. 2002; 123:134-40.

13. Horie Y, Suzuki A, Kataoka E, Sasaki T, Hamada K, Sasaki J, et al. Hepatocytespecific Pten deficiency results in steatohepatitis and hepatocellular carcinomas. J Clin Invest. 2004:113:1774-83.

14. Anstee $\mathrm{QM}$, Goldin RD. Mouse models in non-alcoholic fatty liver disease and steatohepatitis research. Int J Exp Pathol. 2006:87:1-16.

15. Sahai A, Malladi P, Pan X, Paul R, Melin-Aldana H, Green RM, et al. Obese and diabetic $\mathrm{db} / \mathrm{db}$ mice develop marked liver fibrosis in a model of nonalcoholic steatohepatitis: role of short-form leptin receptors and osteopontin. Am J Physiol Gastrointest Liver Physiol. 2004;287:G1035-43.

16. Deng QG, She H, Cheng JH, French SW, Koop DR, Xiong S, et al. Steatohepatitis induced by intragastric overfeeding in mice. Hepatology. 2005;42:905-14.

17. Hill-Baskin AE, Markiewski MM, Buchner DA, Shao H, DeSantis D, Hsiao G, et al. Diet-induced hepatocellular carcinoma in genetically predisposed mice. Hum Mol Genet. 2009;18:2975-88.

18. Raubenheimer PJ, Nyirenda MJ, Walker BR. A choline-deficient diet exacerbates fatty liver but attenuates insulin resistance and glucose intolerance in mice fed a high-fat diet. Diabetes. 2006;55:2015-20.

19. Weltman MD, Farrell GC, Liddle C. Increased hepatocyte CYP2E1 expression in a rat nutritional model of hepatic steatosis with inflammation. Gastroenterology. 1996;111:d1645-53.

20. Okumura K, Ikejima K, Kon K, Abe W, Yamashina S, Enomoto N, et al. Exacerbation of dietary steatohepatitis and fibrosis in obese, diabetic KK-A(y) mice. Hepatol Res. 2006:36:217-28.

21. Fujii M, Shibazaki Y, Wakamatsu K, Honda Y, Kawauchi Y, Suzuki K, et al. A murine model for non-alcoholic steatohepatitis showing evidence of association between diabetes and hepatocellular carcinoma. Med Mol Morphol. 2013;46:141-52.

22. Gans JH. Diethylnitrosamine-induced changes in mouse liver morphology and function. Proc Soc Exp Biol Med. 1976;153:116-20.

23. Travis CC, McClain TW, Birkner PD. Diethylnitrosamine-induced hepatocarcinogenesis in rats: a theoretical study. Toxicol Appl Pharmacol. 1991;109:289-304.

24. He XY, Smith GJ, Enno A, Nicholson RC. Short-term diethylnitrosamine-induced oval cell responses in three strains of mice. Pathology. 1994;26:154-60.

25. Onishi M, Sokuza Y, Nishikawa T, Mori C, Uwataki K, Honoki K, et al. Different mutation patterns of mitochondrial DNA displacement-loop in hepatocellular carcinomas induced by $\mathrm{N}$-nitrosodiethylamine and a cholinedeficient l-amino acid-defined diet in rats. Biochem Biophys Res Commun. 2007:362:183-7.

26. Shimizu K, Onishi M, Sugata E, Sokuza Y, Mori C, Nishikawa T, et al. Disturbance of DNA methylation patterns in the early phase of hepatocarcinogenesis induced by a choline-deficient L-amino acid-defined diet in rats. Cancer Sci. 2007;98:1318-22.

27. de Lima VM, Oliveira CP, Alves VA, Chammas MC, Oliveira EP, Stefano JT, et al. A rodent model of NASH with cirrhosis, oval cell proliferation and hepatocellular carcinoma. J Hepatol. 2008;49:1055-61.

28. Dowman JK, Hopkins LJ, Reynolds GM, Nikolaou N, Armstrong MJ, Shaw JC, et al. Development of hepatocellular carcinoma in a murine model of nonalcoholic steatohepatitis induced by use of a high-fat/fructose diet and sedentary lifestyle. Am J Pathol. 2014;184:1550-61.

29. Nakagawa H, Umemura A, Taniguchi K, Font-Burgada J, Dhar D, Ogata H, et al. ER stress cooperates with hypernutrition to trigger TNF-dependent spontaneous HCC development. Cancer Cell. 2014;26:331-43.

30. Itoh M, Suganami T, Nakagawa N, Tanaka M, Yamamoto $Y$, Kamei $Y$, et al. Melanocortin 4 receptor-deficient mice as a novel mouse model of nonalcoholic steatohepatitis. Am J Pathol. 2011;179:2454-63.

31. Paula Santos N, Colaco A, da Costa RM G, Manuel Oliveira M, Peixoto F, Alexandra Oliveira P. N-diethylnitrosamine mouse hepatotoxicity: Time- related effects on histology and oxidative stress. Exp Toxicol Pathol. 2014; 66(9-10):429-36.

32. Teufelhofer O, Parzefall W, Kainzbauer E, Ferk F, Freiler C, Knasmuller S, et al. Superoxide generation from Kupffer cells contributes to hepatocarcinogenesis: studies on NADPH oxidase knockout mice. Carcinogenesis. 2005;26:319-29.

33. Donnelly KL, Smith Cl, Schwarzenberg SJ, Jessurun J, Boldt MD, Parks EJ. Sources of fatty acids stored in liver and secreted via lipoproteins in patients with nonalcoholic fatty liver disease. J Clin Invest. 2005;115:1343-51.

34. Chitturi S, Abeygunasekera S, Farrell GC, Holmes-Walker J, Hui JM, Fung C, et al. NASH and insulin resistance: Insulin hypersecretion and specific association with the insulin resistance syndrome. Hepatology. 2002;35:373-9.

35. Brennan AM, Mantzoros CS. Drug Insight: the role of leptin in human physiology and pathophysiology-emerging clinical applications. Nat Clin Pract Endocrinol Metab. 2006;2:318-27.

36. Imajo K, Fujita K, Yoneda M, Nozaki Y, Ogawa Y, Shinohara Y, et al. Hyperresponsivity to low-dose endotoxin during progression to nonalcoholic steatohepatitis is regulated by leptin-mediated signaling. Cell Metab. 2012;16:44-54

37. Park EJ, Lee JH, Yu GY, He G, Ali SR, Holzer RG, et al. Dietary and genetic obesity promote liver inflammation and tumorigenesis by enhancing IL-6 and TNF expression. Cell. 2010;140:197-208.

38. Wolf MJ, Adili A, Piotrowitz K, Abdullah Z, Boege Y, Stemmer K, et al. Metabolic activation of intrahepatic CD8+ T cells and NKT cells causes nonalcoholic steatohepatitis and liver cancer via cross-talk with hepatocytes. Cancer Cell. 2014;26:549-64.

\section{Submit your next manuscript to BioMed Central and we will help you at every step:}

- We accept pre-submission inquiries

- Our selector tool helps you to find the most relevant journal

- We provide round the clock customer support

- Convenient online submission

- Thorough peer review

- Inclusion in PubMed and all major indexing services

- Maximum visibility for your research

Submit your manuscript at www.biomedcentral.com/submit 